\title{
Early Childhood Development in Latin America and the Caribbean
}

\author{
Norbert Schady*
}

nschady@worldbank.org

\begin{abstract}
World Bank Policy Research Working Paper 3869, March 2006
The Policy Research Working Paper Series disseminates the findings of work in progress to encourage the exchange of ideas about development issues. An objective of the series is to get the findings out quickly, even if the presentations are less than fully polished. The papers carry the names of the authors and should be cited accordingly. The findings, interpretations, and conclusions expressed in this paper are entirely those of the authors. They do not necessarily represent the view of the World Bank, its Executive Directors, or the countries they represent. Policy Research Working Papers are available online at http://econ.worldbank.org.
\end{abstract}

\footnotetext{
* I would like to thank Francisco Ferreira, Sebastián Galiani, Paul Gertler, André Portela de Souza and participants at the Tenth Annual Meeting of the Latin American and Caribbean Economic Conference held in Paris on October 27-29, 2005 for their comments.
} 


\begin{abstract}
There is considerable evidence that young children in many developing countries suffer from profound deficits in nutrition, health, fine and gross motor skills, cognitive development, and socio-emotional development. Early Childhood Development (ECD) outcomes are important markers of the welfare of children in their own right. In addition, the deleterious effects of poor outcomes in early childhood can be long-lasting, affecting school attainment, employment, wages, criminality, and measures of social integration of adults. This paper considers the theoretical case to be made for investments in early childhood, selectively reviews the literature on the impact of ECD programs in the United States, discusses the evidence from Latin America and the Caribbean, and makes suggestions for future research. The focus is on the relation between outcomes in early childhood and measures of household socioeconomic status, child health, and parenting practices, as well as on the impact of specific policies and programs. The knowledge base on early childhood outcomes is still thin in Latin America and the Caribbean. There are therefore very high returns to comparative descriptive analysis in the region, as well as to careful evaluations of the impact of various programs.
\end{abstract}

JEL Codes: I18, I28, J13, 015 
Children in many developing countries suffer from profound deficits in nutrition, health, fine and gross motor skills, cognitive development, and socio-emotional development. Early Childhood Development (ECD) outcomes are important markers of the "welfare" of children in their own right. In addition, the deleterious effects of inadequate development at early ages can be long-lasting.

There are large differences in cognitive and noncognitive skills or abilities of children at early ages. A well-established finding from the literature on the United States is that children in households with higher income and higher parental education levels have better performance on a variety of cognitive tests (for example, Smith et al. 1997; Blau 1999; Ruhm 2004; Taylor et al. 2004), and lower incidences of behavioral problems (for example Berger et al. 2005). Steep socioeconomic gradients between socioeconomic status and early childhood skills have also been found in Latin America, including in Brazil (Halpern et al. 1996) and Ecuador (Paxson and Schady 2005). Differences in test performance across children persist as these children age. Moreover, research from a number of developed countries suggests that low levels of cognitive development in childhood, as measured by tests administered as early as 22 months of age, are important predictors of wages (for example Connolly et al. 1992; Currie and Thomas 1999; Feinstein 2003; Robertson and Symons 2003). Others have argued that non-cognitive dimensions of development in early childhood are important determinants of future success (Carneiro and Heckman 2003; Cunha et al. 2005). Inadequate cognitive and noncognitive skills can therefore contribute to the transmission of poverty across generations.

A variety of interventions in early childhood have been shown to have large returns. In the United States, children who were randomly assigned to the Perry Preschool Program had higher test performance later on in life, lower incarceration rates, and median earnings that were more than one-third higher than those in the control group (Schweinhart 2005; Currie 2001; Carneiro and Heckman 2003). Similarly impressive results have been found in analyses of the pilot Carolina Abecederian Project. There also appear to be substantial, if smaller returns to the nationwide Head Start program — for example, Garces et al. (2002) find that Head Start participants are more likely to attend college and have lower rates of delinquency and crimealthough there is some question about cost-effectiveness (Currie 2001; Berger et al. 2005). In Latin America and the Caribbean, Grantham-McGregor and her co-authors find large effects of an early childhood stimulation pilot intervention on test performance in Jamaica (GranthamMcGregor et al. 1991; 1997; Walker et al. 2000; Powell et al. 2004); Behrman, Cheng, and Todd (2004) report large effects of a daycare program on motor skills, psychosocial skills and language acquisition in Bolivia. Berlinski and Galiani (2005) and Berlinski et al. (2005) show that a 
preschool construction program in Argentina increased preschool enrollment rates, and led to better performance on cognitive and behavioral outcomes among preschool participants once they reached primary school.

This paper discusses Early Childhood Development in Latin America and the Caribbean. Explicit reference is not made to child health and nutrition per se, as this has been extensively studied in the region. The focus is on the development of cognitive and noncognitive skills or abilities of children in the preschool years. A handful of recent papers have suggested that there are very serious deficits in cognitive development among children in Latin America (Fernald et al. 2005 and Gertler and Fernald 2004 on Mexico; Halpern et al. 1996 on Brazil; Paxson and Schady 2005 on Ecuador). Less is known about levels of noncognitive skills in the region.

The paper is organized as follows. Section 1 briefly considers the theoretical case to be made for investments in early childhood. Section 2 selectively reviews the literature on the impact of ECD programs in the United States. Section 3 focuses on Latin America and the Caribbean. It discusses evidence on developmental deficits in the region, the relationship between child development, household socioeconomic status, child health, and parenting practices, and the impact of specific programs and policies. Section 4 proposes directions for future research. An important message of this section is that the knowledge base is still thin in Latin America. There are therefore very high returns to comparative descriptive analysis of ECD outcomes in the region, as well to careful evaluations of the impact of various programs and policies.

\section{The theoretical case for investments in early childhood}

The economic case for public investments in early childhood has been made strongly by a number of authors. This section briefly summarizes the arguments made in a recent, influential article by Cunha et al. (2005). Cunha et al. develop a model of human skill formation that builds on Becker (1964), Becker and Tomes (1979; 1986) and Ben-Porath (1967). Their model has a number of important insights. First, abilities are multidimensional, rather than unidimensional in the sense of Griliches (1977). (Cunha et al. use “skills” and “abilities” interchangeably.) Cognitive and noncognitive abilities both affect schooling and wages. Pure cognitive abilities include IQ; noncognitive abilities include things like patience, self-control, temperament, and time preference. Abilities are shaped by genetic components and environmental influences, and the influence of parents is particularly important. Second, ability formation is governed by a multistage technology. Some abilities can be produced more effectively at a given period in life; Cunha et al. refer to these as "sensitive" periods. Other abilities can only be produced at a particular period; Cunha et al. refer to these as “critical” periods. "Sensitive” and "critical” 
periods mean that remediation of some abilities not acquired in early childhood is impossible or prohibitively costly. In the extreme case of a Leontieff technology, investments in skill formation during the school or post-school periods are only productive if a sufficiently high level of investments was made earlier on. Third, there is "self-productivity" in skill formation, so that skills acquired in one period persist into the next period, and skills acquired in one dimension (for example, self-control) may make it easier for a person to acquire skills in another dimension (for example, cognitive learning). Fourth, there is "complementarity” of skills, such that skills acquired in one period increase the productivity of investments at later ages. Finally, as a result of self-productivity and complementarity, Cunha et al. argue that investments at early ages can have important multiplier effects.

An important question that arises is why, if the model in Cunha et al. (2005) is correct, parents do not invest more in developing critical skills of their children at early ages. What is the market failure? One possibility is that parents are credit constrained. As Carneiro and Heckman (2002; 2003) and Cunha et al. discuss, there are two possible forms of credit constraints that could affect investments in early childhood. First, the timing of income may matter. Even those parents whose expected lifetime income is high enough to allow them to make adequate investments in early childhood may have insufficient resources at their disposal when their children are young. If these parents are credit constrained, they may under-invest in skills formation in early childhood. Second, the lifetime income of some parents may be too low for them to borrow sufficiently against it; this too could result in inadequate investments in early childhood. Carneiro and Heckman (2002; 2003) and Cunha et al. argue that the first kind of credit constraint is empirically unimportant in the United States, while the second kind of credit constraint appears to limit investments in early childhood. But, it is not clear whether this empirical evidence can be applied to developing countries, including those in Latin America and the Caribbean.

Another reason for under-investment by parents in early childhood skill formation may arise from information failures. This is not discussed at great length in Carneiro and Heckman (2002; 2003) or Cunha et al. (2005). However, it may be a particularly important consideration in developing countries, where education levels are much lower than those found in the United States. It is generally believed, although hard to demonstrate empirically, that low parental education levels play a causal role explaining poor child health status in developing countries; much the same is likely to apply to other dimensions of skill formation in early childhood. To the extent that this is the case, inadequate knowledge by parents about the returns to investments in childhood, about the benefits of specific policies or programs, and about parenting practices may 
all contribute to low levels of investment in skill formation at early ages, or to environments that do not promote the acquisition of important cognitive or noncognitive abilities by children.

Finally, there may also be equity considerations for public investments in early childhood. Efforts to equalize initial endowments avoid many of the moral hazard problems inherent in programs that seek to equalize outcomes in adulthood. Young children do not reduce their effort in response to an early stimulation program, but adults may work less if they know they are eligible for unemployment benefits. In the language of the World Bank's 2006 World Development Report, Equity and Development, it may therefore be more effective to promote equality of opportunities (in early childhood) than equality of outcomes (in adulthood) (World Bank 2005a; see also Currie 2001).

\section{Evidence on returns to investments in early childhood in the United States}

If the theoretical case for investments in early childhood is sound, one would expect to see high returns to programs that effectively build skills early in the life cycle. This section briefly discusses the empirical evidence from the United States, focusing on findings from two randomized evaluations of pilot interventions, as well as on evaluations of the impact of the Head Start program.

The Perry Preschool Program is probably the most-studied preschool intervention in the United States. Between 1962 and 1967, a sample of 128 low-income African-American children ages 3 or 4 who were assessed to be at high risk of school failure were randomly assigned into treatment and control groups. The treatment group received a half-day preschool every weekday

plus a weekly home visit—both for eight months of the year, for two years. Project staff collected data on both study groups from ages 3 to 11, and again at ages 14, 15, 19, 27 and 40. Analysis of these data showed that the treatment group outperformed the control group on a variety of measures of educational attainment, including lower grade repetition, higher rates of high school graduation, and higher performance on various intellectual and language tests up to age 7, school achievement tests at ages 9, 10, and 14, and literacy tests at ages 19 and 27. At age 40, those who received the preschool intervention had median earnings that were more than one-third higher than those who did not, were significantly more likely to be employed, had lower fractions of lifetime arrests, and were sentenced to significantly fewer months in prison (Schweinhart 2005; see also Currie 2001; Carneiro and Heckman 2003).

The Carolina Abecederian Project provided a particularly intensive intervention: At birth, children were randomized into a treatment group that received "enriched center-based child care services emphasizing language development for eight hours per day, five days a week, 50 weeks 
per year, from birth to age five” and a control group (Currie 2001). At school entry, the study children were again randomized into two groups, one of which received no further intervention, and another which received a "Home-School Resource Teacher". At age 15, the children who had received the preschool intervention had higher scores on achievement tests, and reductions in the incidence of grade retention and special education. (Children who are placed in a special education "track" are generally more likely to drop out of school in the future.) The effects of the Home-School Resource Teacher were either small or insignificant. At age 21, the children exposed to the Abecederian intervention had higher average test scores, and were twice as likely to be still in school or to have ever attended a four-year college.

The evaluations of the Perry Preschool Project and the Carolina Abecederian Project provide "laboratory" evidence of the possible returns to investments in early childhood. However, these "model” interventions are typically funded at higher levels and are administered by staff who are more motivated and better trained than staff at large-scale programs. Moreover, as in many clinical trials, the sample sizes in these evaluations are generally very small—less than 100 children in the treatment and control groups each. It is therefore important to complement these evaluations with analysis of the impact of Head Start, the largest program for disadvantaged preschool children in the United States.

Head Start, created in 1965 as part of the Johnson administration's "War on Poverty”, provides disadvantaged children with (predominantly part-day) preschool programs. In 1999, the program covered 800,000 children—almost 50 percent of eligible three and four year-old children—and received $\$ 4.7$ billion of federal funding (Currie 2001). There has never been a large-scale, randomized evaluation of Head Start, so evaluations have relied on a variety of techniques to construct comparison groups-for example, comparing children who attended Head Start with others who did not (Lee et al. 1990), comparing siblings who attended Head Start with those who did not (Currie and Thomas 1995), or comparing children in schools which offered Head Start for two years with those which offered it for three years (Reynolds 1998). These are serious attempts to correct for the potential endogeneity of participation in Head Start. However, the results may still be biased if self-selection into Head Start on the basis of unobservables is important—for example, if parents are more likely to enroll children who have learning difficulties or, alternatively, enroll promising children they expect would benefit most from the program (see Todd and Wolpin 2003 for a general discussion of these issues).

With this caveat in mind, the studies that are methodologically most sound generally report significant effects of Head Start. Children who attended Head Start are less likely to be enrolled in special education when they reach school, more likely to make adequate grade 
progress, less likely to drop out of high school, and have significantly higher test scores. Longerterm studies also find higher rates of college attendance (for whites) and lower rates of delinquency and crime (for blacks) among program participants (Garces et al. 2002).

A number of studies have analyzed the effect of Head Start on child socio-emotional development. This is important because child attributes as basic as being able to sit still and pay attention are necessary for any reasonable amount of learning to take place in school. Children who are appropriately socialized tend to turn into better-adjusted adults, and the labor market returns to various non-cognitive skills, including motivation, enthusiasm, cooperation, and teamwork may be as large as or larger than those to "IQ" and other dimensions of cognitive development (Carneiro and Heckman 2003; Heckman and Rubinstein 2001). Behavioral problems in early childhood have also been shown to be strong predictors of high school dropout and delinquency.

There is some controversy about the effects of center-based programs like Head Start on child socio-emotional development. At what age, and under what circumstances, is it beneficial for young children to spend large amounts of time away from their mothers? The analysis of the Perry Preschool Project and the Carolina Abecederian Project suggest that, whatever the negative effects of the intervention may be on mother-child attachment and (possibly) child socioemotional development, these are offset by the positive effects on academic achievement, wages and criminality — at least for the high-risk populations that participated in these model programs. That being said, it is not clear how easy it is to extrapolate from such model programs to large, publicly-funded or implemented programs like Head Start. Two recent papers are here informative. A randomized evaluation of the Early Head Start program, which combines centerbased preschool with parent-child group socialization activities and parent education, either center-based or during home visits, suggests that children participating in Early Head Start exhibit less aggressive behavior, less negative behavior towards parents, and are better able to pay sustained attention during play (Blau and Currie 2004). This is consistent with earlier evidence that Head Start had positive effects on measures of social adjustment of children, including impulse control (Lee et al. 1990, cited in Currie 2001). On the other hand, research by Magnuson et al. (2004) suggests that children in pre-kindergarten programs, as well as children participating in Head Start, were more likely to exhibit aggressive behavior and were less able to exercise selfcontrol. It is not clear what explains these differing findings. Part of the explanation may be that there are very large differences in quality across different child care options and Head Start sites: By some estimates, as many as 40 percent of children in the United States are attending child care 
judged to be of low quality (Danziger and Waldfogel 2000; see also the discussion in Currie 2001).

Head Start and similar center-based programs seek to improve school readiness by providing a nurturing learning environment in the pre-school years. These programs focus on the child, rather than on parents. Yet there is widespread consensus that parenting also "matters" for development in early childhood, and a number of programs have been designed to improve parenting behavior.

Center plus preschool programs combine preschool with regular discussions with parents. These programs have been shown to have positive effects on nurturance and, in some cases, reductions in spanking, increases in the use of reasoning as a disciplining device, and improvements in parents' abilities to assist in child problem-solving activities (Brooks-Gunn and Markham 2005). As with the "regular" preschool programs, center plus programs also have positive effects on child cognitive development and school readiness. Disentangling the causality is hard: What fraction of the improvements in child outcomes are a result of the observed changes in parenting practices rather than of the participation in the preschool component of the program? These difficulties notwithstanding, it appears that as much as half of the observed changes in child outcomes can be attributed to improvements in parenting (Brooks-Gunn and Markham).

The evidence on the effectiveness of home visiting programs is decidedly more mixed. Home visiting programs send trained staff into homes of families with young children to encourage changes in parenting practices. The exact nature of the intervention varies by program, but programs typically attempt to provide parents with social support, practical assistance, and education about parenting and child development. Gomby et al. (1999) summarize evidence on the impact of six programs which included a randomized evaluation, and which jointly covered as many as 550,000 children in the United States. Most of the evaluations provide some evidence of improved parenting and home environment outcomes, although (worryingly) differences between treatment and control groups were more often found for parent-reported measures than for those assessed by enumerators. In some cases, participation was also associated with lower rates of child abuse, neglect and other forms of child maltreatment. Results on changes in measures of children's behavior were mixed. In one study, no program effects were found on parent-reported child behavior for participants in the Comprehensive Child Development Program. In another study, children who had participated in the Elvira Nurse Home Visitation Program were re-visited when they were 15 years old, 13 years after the end of the intervention. There were no differences between treatment and control groups in measures such as acting out in school, suspensions, initiation of sexual intercourse, or major acts of delinquency, although children who had been 
exposed to the program reported fewer instances of running away, fewer arrests and convictions, fewer cigarettes smoked per day, fewer days having consumed alcohol in the last six months, and less lifetime promiscuity. None of the evaluations of home visiting programs found consistent evidence of improvements on a variety of tests of child development and achievement (Gomby et al.; Brooks-Gunn and Markham 2005).

A selective review of ECD programs in the United States holds a number of important lessons for Latin America. First, carefully designed and implemented pilot programs such as the Perry Preschool Project and the Carolina Abecederian project have had very large benefits for participants. One calculation of returns to enriched programs like the Perry Preschool Program or the Carolina Abecederian Project, targeted to high-risk disadvantaged minority male youth in the United States, suggests that the costs would more than pay for themselves in reduced incarceration rates alone (Donohue and Siegelman 1998, cited in Carneiro and Heckman 2003). The evaluations of these programs bolster the theoretical case made by Carneiro and Heckman (2003) and Cunha et al. (2005) that investments in skills in early childhood can have high returns. But these programs are very intensive, and are run by highly-motivated professional staff, so it is hard to know to what extent the estimated effects can be replicated in nationwide programs. Evaluations of Head Start, the largest preschool program in the United States, also show improved outcomes among participants. However, there is some uncertainty about the costbenefit ratio of Head Start-in part, because it is hard to quantify the expected medium- and longterm benefits (Currie 2001). Some authors have argued that simple income transfers to poor households compare favorably with Head Start in terms of cost-benefit ratios (Taylor et al. 2004; Berger et al. 2005). This discussion suggests that there are high returns to experimenting with, and carefully evaluating the impact of a variety of programs in Latin America and the Caribbean, both on a small-scale pilot basis and on a larger scale.

Second, interventions in early childhood in the United States have been shown to have the largest impact on outcomes when they are carefully targeted to poor households, and to households with the largest ECD deficits. Cunha et al. (2005) stress this point when they argue that there is no trade-off between efficiency and equity for investments in early childhood. In the Abecederian model program, all of the children were judged to be at risk of mental retardation, but the positive effects of the program were twice as large for children from the poorest and least educated families (Currie 2001). The randomized evaluations of Early Head Start and the Infant Health and Development Program both suggest that improvements in parenting behaviors among black mothers were larger than among white mothers (Love et al. 2002, cited in Brooks-Gunn and Markham 2005). Improvements in a variety of ECD outcomes were also larger for children of 
mothers with high school education or less than for those with some college or more, and (less clearly) for mothers with low psychological resources, including initially higher incidences of maternal depression (Brooks-Gunn and Markham 2005). Currie (2001) and Currie and Thomas (1999) also argue that ECD improvements associated with Head Start were concentrated among participants who were most vulnerable. Finally, Currie and Thomas (1999) find that gains in test scores for Head Start participants are at least as large for Hispanic children as for non-Hispanic whites. Moreover, the effects tended to be larger among children whose mothers had been interviewed in Spanish, a result Currie and Thomas attribute to the importance of exposure to the “mainstream” language. As is discussed below, there is evidence of steep gradients between performance on various tests of development in early childhood and socioeconomic status in Latin America. This suggests that serious thought needs to be given to the question of how best to target interventions that can improve skills of children in the preschool years in Latin America and the Caribbean.

Third, even when a given input into child development is important, the policy prescriptions may not be obvious. This is particularly apparent with interventions that try to improve parenting behavior. By and large, the results from the evaluations of home visiting programs in the United States are disappointing. Part of the problem appears to be that home visiting programs suffer seriously from attrition—even among those parents who are initially willing to participate in home visiting programs, a large number (often more than half) drop out of the program, and those who stay generally receive many fewer visits than was originally anticipated. Gomby et al. (1999) make a compelling case that this is partly a result of program goals and design —often programs seek to convince parents to change behaviors that they themselves may not view as negative. A further problem with home visiting programs in the United States is that they have suffered from a great deal of staff turnover. Such staff turnover is particularly debilitating in interventions that rely on trust between home visitors and families. As is discussed below, there is evidence from Ecuador that inadequate parenting practices are strongly associated with gaps in cognitive development at early ages, and evidence from Jamaica that suggests that small-scale pilots that focus on parenting and early childhood stimulation can have high returns. A review of studies from the United States shows that, in scaling up, it is important to design interventions that are attractive to the households they are intended to benefit.

Fourth, careful consideration needs to be given to the relationship between investments in early childhood and the formation of skills at later ages. Cunha et al. (2005) stress that it may be impossible or prohibitively costly to make up some deficits in skills at later ages, and that skills formed in early childhood make it easier to acquire further skills later on. A related question is 
whether there are investments in later periods that are necessary for the benefits of early childhood investments to be sustained. Analysis of Head Start is here instructive. Currie and Thomas (1995) find that the initial Head Start program impacts on vocabulary and reading test scores are similar for whites and blacks, but that gains for Head Start participants quickly "fade out” in primary school for black children but not for white children. There are various possible explanations for such differences in the impact of the program by race. One explanation is that there are differences in the impact of Head Start itself-the program may not serve black children as well as white children. Another explanation is that there are differences in the experience of children after they leave Head Start: Black children who attended Head Start may have family, neighborhood, or school environments that are less conducive to learning than other black children, whereas white children who attended Head Start are not disadvantaged relative to other white children. Currie and Thomas (2000) explore this question and conclude that the fade out of gains for black children is a result of the lower-quality schools they attend after Head Start. In a similar vein, Fryer and Levitt (2004) argue that the gap in test scores between black and white children becomes larger after kindergarten because of differences in the quality of schooling. Little is known for Latin America and the Caribbean about the interaction between, on the one hand, investments in early childhood and, on the other hand, school quality and other dimensions of the environment later in a child's life.

\section{Evidence on early childhood outcomes in Latin America and the Caribbean}

Although there is a wealth of data in the medical, sociological and economic literature on the health and nutritional status of infants and young children in Latin America, relatively little is known about other dimensions of their welfare. This section discusses some recent research which focuses on motor skills, cognitive development, and socio-emotional development in early childhood. The discussion is grouped around three themes. First, what is known about aggregate, nationwide deficits in investments in early childhood in Latin America? Second, within a particular country or sample, is there evidence of a gradient between outcomes in early childhood and household socioeconomic status? And, to the extent that such a gradient is apparent, what are the channels through which income or other measures of household welfare affect outcomes in early childhood? Finally, what evidence is available on the impact of various policies or programs?

International comparisons of preschool investments: Comparable international data on the development of cognitive and noncognitive skills among children of preschool age are sparse, especially in developing countries. The only measure for which information is available for a 
large number of countries is enrollment in preschool. This section therefore begins with an analysis of preschool enrollment rates in Latin America.

Table 1 presents statistics on the gross preprimary enrollment rate for individual countries in Latin America and the Caribbean, as well as averages for the region. Data are from databases of the World Bank (World Bank 2005b); they include 144 countries, and refer to the year 2000. For each country or region, the table presents three figures. The first column gives the gross primary enrollment rate. The second and third columns are based on regressions of gross preprimary enrollment on a polynomial in per capita GDP, including GDP level, its square, cube, and quartic, as well as a dummy variable for a given country or region. (In the second column, each country observation is weighted by its population, while the third column provides the results from unweighted regressions.) The table reports the coefficient on a country or region dummy, and notes when the coefficient is significant. These regressions therefore benchmark performance in a country or region by comparing it with other countries of similar income levels.

The results from these regressions are informative. Taken as a whole, Latin America and the Caribbean does not appear to have a deficit in preschool enrollment: The (weighted) average of the gross enrollment rate across countries in the region is 61.1 percent. This is above what would be expected for the income level of the region - the coefficient on the dummy for Latin America and the Caribbean is positive, although it is not significant. However, there is a great deal of variation across countries. A handful of countries are "over-performers" in terms of preprimary enrollment rates, including Bolivia, Costa Rica, Ecuador, Guatemala, Jamaica, and Peru. By contrast, a number of other countries are “under-performers”, including Argentina, the Dominican Republic, Honduras, Panama, and Venezuela. Put differently, preprimary enrollment is essentially the same in Argentina and Peru, although per capita GDP in Argentina is roughly four times that in Peru; per capita GDP is higher in Venezuela than in Costa Rica, but preprimary enrollment is almost 40 percentage points higher in Costa Rica.

Simple comparisons of countries like those presented in Table 1 have obvious limitations. The analysis of over- or under-performers may be misleading if enrollment in the average country is "too low" or "too high". For example, if there truly are high returns to preprimary enrollment, and if most countries invest little in preschool, even some of the apparently over-performing countries may benefit from expansions in coverage of preschool. Another problem with these comparisons is that they obviously abstract from quality differences across countries; relatedly, coverage of the preschool system need not be a good indication of the development of a given set of skills or competencies. Nonetheless, enrollment in preschool is often thought to have important benefits for participants, and the evidence for at least one country in Latin America, Argentina, 
discussed in detail below, suggests that children who enroll in preschool have superior learning outcomes later on. The results in Table 1 are therefore an indication that there is scope in many countries in the region for expansions in preschool coverage.

Evidence of deficits in early childhood outcomes and socioeconomic gradients within countries: A handful of recent papers have used micro-level data to describe deficits in early childhood outcomes in Latin America and the Caribbean, and to make comparisons of households with different levels of education, wealth, or income.

Fernald et al. (2005) and Gertler and Fernald (2004) present evidence of ECD shortfalls in Mexico. Fernald et al. focus on the relationship between deficits in child nutritional status and the Mental Development Index (MDI) of the Bayley Scales of Infant Development, a test of memory, learning, problem-solving, sensory-perceptual acuities, and receptive and expressive language development. Fernald et al. find significant reductions in the Bayley MDI scales with the age of the child: At age 13-14 months, 14.4 percent of children are one standard deviation or more below the normed value for the test, and 3.0 percent are 2 standard deviations or more below. By age 21-23 months, almost half the children are 1 standard deviation below the norm, and 11.3 are more than 2 standard deviations below. These deficits in mental development are mirrored by an increasing fraction of children with low height for age—at age 13-14 months, 25.9 percent of the children are stunted, compared to 42.7 percent by age 21-23 months. However, Fernald et al. find no association between height for age and the Bayley MDI score once family and environmental variables are included in a multivariate regression framework. More surprisingly, none of the parental or socioeconomic factors they control for, including income, employment, parental age, education, and whether the head of the household spoke an indigenous language, are significant predictors of performance on the Bayley MDI score.

Gertler and Fernald (2004) use a large number of tests to assess developmental outcomes for a sample of poor children in Mexico. These include the Woodcock-Johnson-Munoz test, a set of co-normed tests that measure general intellectual ability, specific cognitive abilities, and scholastic aptitude which has been used in Latin America (Lozoff et al. 1991; Rodriguez and Prewitt-Diaz 1990; Roselli et al. 2001); and the Test de Vocabulario en Imágenes Peabody (TVIP), the Spanish version of the Peabody Picture Vocabulary Recognition Test (PPVT). The TVIP is a test of receptive language that is frequently used to evaluate Spanish-speaking preschool children (Munoz et al. 1989; Umbel et al. 1992). Data collection was carried out for an evaluation of the impact of Oportunidades, the cash transfer program — further details on this are provided below. Gertler and Fernald compare the cognitive development outcomes of the Oportunidades evaluation sample with the population that was used to norm a given test. On the 
basis of these comparisons, Gertler and Fernald argue that children in the evaluation sample appear to have very serious cognitive deficits. On average, they place in the $17^{\text {th }}$ percentile for vocabulary on the TVIP, and in the $15^{\text {th }}$ percentile for long-term memory, the $22^{\text {nd }}$ percentile for short-term memory, and the $7^{\text {th }}$ percentile for visual integration in the Woodcock-Johnson-Munoz test. The results presented by Gertler and Fernald are not disaggregated by the age of the child, so it is not clear whether the pattern observed by Fernald et al. (2005) using the Bayley scoreslarger deficits for older children-is also apparent in this sample and with these outcomes.

Halpern et al. (1996) use the Denver Test to analyze deficits in gross and fine motor skills, language development, and adequate socialization of a sample of children born in hospitals in Pelotas, Rio Grande do Sul, Brazil (see also Victora et al. 1989). The authors conclude that about one-third (34 percent) of children show developmental deficits. There are clear gradients by household income, and these persist after corrections are made for birthweight. (Children born in households with lower socioeconomic status have lower birthweights.) Moreover, Halpern et al. find that the income gradients they observe become larger with the age of the child.

Paxson and Schady (2005) use data on a sample of poor children in Ecuador to study the determinants of child cognitive development, as measured by performance on the TVIP. They show that the age-normed TVIP score declines steadily between 3 and 6 years of child age. This decline in the mean is accompanied by an increase in dispersion. Paxson and Schady graph the $90^{\text {th }}, 50^{\text {th }}, 25^{\text {th }}$ and $10^{\text {th }}$ percentiles of the TVIP scores at each age. They show that the $90^{\text {th }}$ percentile scores are relatively constant with age, and there are modest declines in the median; by contrast, scores for children at the $25^{\text {th }}$ and $10^{\text {th }}$ percentiles of the distribution decline sharply with age.

What factors are responsible for the increasing dispersion in test scores with age? Paxson and Schady (2005) first use simple graphs to analyze this question. Figure 1, taken from their paper, shows that the median TVIP score for children born to parents with low levels of education or low levels of household wealth falls dramatically with the age of the child. By contrast, the score remains roughly constant for children in wealthier households or with more educated parents. Finally, Figure 1 shows that there are no differences between the scores of urban and rural children in their sample. The effects of socioeconomic status on test performance are large: Paxson and Schady estimate that a child whose family falls at the $90^{\text {th }}$ percentile for wealth, maternal education and paternal education is predicted to have a score that is approximately two standard deviations higher than a child at the $10^{\text {th }}$ percentile for each of these variables. Paxson and Schady also consider the relationship between cognitive outcomes, socioeconomic status, and measures of child nutritional status. They show that nutritional status, in particular hemoglobin 
levels, is significantly associated with test performance. However, measures of nutritional status account for only a small fraction of the association between wealth, parental education and TVIP scores.

An innovative feature of the data collected in Ecuador is that it includes information on parenting quality, including the Home Observation for Measurement of the Environment (HOME) scale, which has been widely used in research in the United States (Bradley 1993; Caldwell and Bradley 1984; Bradley et al. 2001). This is constructed from 11 items that are assessed by enumerators at the close of the interview, and measures punitiveness (for example, whether parents yelled at or hit children during the interview), and responsivity to children (for example, whether they responded to and encouraged children in a positive way during the interview). Each item is scored as a dichotomous variable, and the final scale ranges from 0 to 11 , with higher values corresponding to less responsive and harsher behavior. Paxson and Schady (2005) show that children whose parents have lower (better) HOME scores, reflecting warmer and less punitive behavior, have significantly higher TVIP test scores. Interestingly, the parenting measures account for a substantial fraction of the associations between socioeconomic status and cognitive development that are observed in the data.

A number of broad conclusions can be drawn from the papers on Mexico, Brazil, and Ecuador. First, when comparisons are made of the performance of children in Latin America with the reference populations that were used to norm the tests, Latin American children show large developmental deficits. Second, there appear to be sharp gradients by socioeconomic status. Children from poorer households, and children with parents with lower education levels perform significantly worse than other children. Third, the gradient between socioeconomic status and child development appears to become stronger with age. This may be because the protective effect of socioeconomic status is cumulative, as Paxson and Schady (2005) speculate, which would be consistent with the model in Cunha et al. (2005). It is also possible that some of the tests that are used are better suited for older children. Note that it would not be appropriate to conclude from this evidence that it is the older ages that are critical for child development-it may well be that insults suffered earlier on only manifest themselves somewhat later. Fourth, child nutritional status and measures of parenting status are both significantly associated with performance on a number of tests of early development.

Policies and programs to improve skills formation among young children in Latin America and the Caribbean: Recent analysis of the impact of programs on outcomes in early childhood in Latin America and the Caribbean has focused on conditional cash transfers 
(Mexico), access to preschool (Bolivia and Argentina), and food supplementation and early stimulation interventions (Jamaica).

Gertler and Fernald (2004) analyze the impact of Oportunidades, the conditional cash transfer program, on a large set of ECD outcomes. Oportunidades makes large cash transfers, as much as 20 percent of household income, conditional on households making regular, monitored visits to health centers. During these visits children are immunized, their growth is monitored, and they are given micronutrient supplements; parents receive education on health, nutrition, and hygiene.

To analyze the impact of Oportunidades on ECD outcomes, Gertler and Fernald (2004) focus on two comparisons. First, they compare children who received Oportunidades transfers with a comparison group of children who did not receive transfers. This comparison group was constructed with matching techniques: A group of communities that was not eligible for Oportunidades was selected for the evaluation, and matching and regression techniques are used to adjust for differences between households in the treatment and comparison groups. Second, they compare households in communities that received Oportunidades transfers for different amounts of time. This control group was constructed by randomization: As part of the evaluation design, a lottery was used to assign communities into two groups, one of which received transfers for 12 to 18 months longer than the other.

Using the treatment and matched comparison groups, Gertler and Fernald (2004) find significant differences in motor skills: On average, outcomes are 15 percent higher among boys and 10 percent higher among girls in the treated communities than among similar children in the comparison communities. Children in the treated communities also appear to have fewer socioemotional problems, although the effect is only statistically significant for girls. There is no clear pattern of program effects on any of the measures of cognitive development. Finally, the authors show that there is no evidence that the duration of program exposure, as measured by the difference between the two random assignment groups, has a significant impact on any outcome-motor skills, socio-emotional problems, or cognitive development.

Behrman, Parker and Todd (2004) focus on schooling outcomes of children exposed to Oportunidades during their pre-school years. Like Gertler and Fernald (2004), Behrman, Parker and Todd make two comparisons_-first, between households that received Oportunidades transfers and the matched set of communities that never received transfers, and second, between communities that were randomly assigned to different amounts of program exposure. Behrman, Parker and Todd show that children who were exposed to Oportunidades between ages 0 and 6 were likely to subsequently enter school at a slightly earlier age, were more likely to progress on 
time, and more likely to have higher years of completed schooling as they begin to enter school. As in Gertler and Fernald, program impacts are generally apparent in the comparisons between the treatment and matched comparison groups, and not in the comparisons between the two treatment groups that were randomly assigned to different amounts of program exposure.

Three recent papers analyze the effects of daycare or preschool attendance in Bolivia and Argentina. Behrman, Cheng, and Todd (2004) use non-experimental data to evaluate the impact of a Bolivian pre-school program, the Proyecto Integral de Desarrollo Infantil, or PIDI. The outcome measures include "a battery of tests of bulk motor skills, fine motor skills, language and auditory skills, and psychosocial skills”. (The authors do not provide details on the exact nature of these tests.) The PIDI program provides full-time daycare, nutritional and educational services to children between the ages of 6 and 72 months in low-income areas. Behrman, Cheng, and Todd use propensity score matching to estimate program impacts. First, they compare program participants with a matched comparison group of non-participants - they refer to these as average treatment impacts. Second, they compare participants with different amounts of exposure to the program - they refer to these as marginal treatment impacts. The identifying assumption for the estimates of average treatment impacts is that there is no selection into the program on the basis of unobservable characteristics of households or children. This restriction is loosened somewhat in the estimates of marginal treatment impacts although, conditional on program participation, unobservables are still not allowed to determine the duration of exposure.

Behrman, Cheng, and Todd (2004) find that, in the comparison of treated and untreated children, there is some evidence of positive program impacts on bulk and fine motor skills, psychosocial skills, and language acquisition. These impacts are concentrated among children ages 37 months and older-for the younger children, ages 6-36 months, the estimated program effects are generally insignificant, and are as likely to be positive as negative. When the results are disaggregated by the length of exposure, effects are most clearly observed among children who have been exposed to the PIDI program for more than a year. Behrman, Cheng, and Todd also calculate cost-benefit ratios for the PIDI program. This is an important concern: At the time of the evaluation, the cost of the PIDI program was approximately $\$ 43$ per month, in a country with per capita annual GDP of \$800 in exchange-rate converted pesos, and \$2,540 in PPP terms. The PIDI program is estimated to have an impact on height, cognitive development, and schooling of participating children. Behrman, Cheng, and Todd heroically combine these estimated program impacts with data on wages from Bolivia and a number of other countries to argue that there are positive cost-benefit ratios to PIDI under a variety of plausible assumptions and discount rates. 
A recent paper by Berlinski and Galiani (2005) analyzes the impact of a large program to construct pre-school facilities in Argentina in the 1990s on pre-primary school attendance and maternal labor supply. The intensity of the program varied by region, and Berlinski and Galiani use a differences in differences framework to identify program impact. The estimation also includes cohort and region dummies to control for nationwide trends and level differences across regions. The identifying assumption is therefore that regions that received more preschool facilities would not have had different growth rates in enrollment in the absence of the construction program. (Berlinski and Galiani provide evidence that this is a reasonable assumption.) Berlinski and Galiani conclude that the program had a large, positive impact on preschool enrollment-indeed, they cannot reject the null hypothesis that all new preprimary school slots were taken up by children who would otherwise not have been in school. The authors take this as strong evidence for a supply constraint on preschool enrollment in Argentina.

A follow-up paper by Berlinski et al. (2005) analyzes the impact of the preschool construction program on test performance in Spanish and mathematics in third grade. The analysis provides compelling evidence of significant program impacts. Intent-to-treat estimates show that children in cohorts and regions exposed to the construction program have significantly higher test scores. Preschool participants also appear to perform better on noncognitive dimensions of development, including paying attention in class, being disciplined, and being participative, as reported by their third-grade teachers. Convincingly, Berlinski et al. provide evidence from a "placebo experiment" which shows that children in these same schools in other cohorts that were not affected by the preschool construction program do not appear to have higher test performance-an important check on their identification strategy.

Various papers by Grantham-McGregor and her co-authors use data from Jamaica to analyze the short- and medium-term impact of interventions in early childhood. In one study, a lottery was used to divide a sample of stunted children ages 9-24 months into four groups: The first study group received a food supplement of $1 \mathrm{~kg}$. of milk-based formula provided weekly; a second study group received early childhood stimulation, specifically weekly home visits by social workers who demonstrated play with home-made toys and discussed parenting issues with mothers; the third study group received both the supplement and the stimulation; the fourth group served as a control group. In addition, data was collected on a sample of non-stunted children. Children in all of the study groups were then followed over time. Results after two years suggested that both the stimulation and nutritional supplement interventions had positive impacts on child development as measured by the Griffiths Mental Development Scales. The largest effects were found in the group that had received both interventions-after two years these 
children had caught up with the matched group of non-stunted children (Grantham-McGregor et al. 1991).

Children in the original study were re-visited at ages 7-8, and again at 11-12 years. Disappointingly, these results showed that the study group that received only nutritional supplements did not have better outcomes than the control group on a variety of tests of cognitive development. By contrast, the group that had received stimulation only and that which had received both interventions performed better than the control group on 9 of the 11 tests that were applied, and significantly better in three (Grantham-McGregor et al. 1997; Walker et al. 2000). In a related study, undernourished children age 9 to 30 months and their mothers were randomly assigned to a treatment group which received stimulation, including weekly home visits by community health aides, and a control group. After one year, children who had received the stimulation intervention had significantly better outcomes in three of four subscales from the Griffiths Mental Development Scales. Mothers in the intervention group also had better knowledge of childrearing and childbearing practices (Powell et al. 2004).

A number of conclusions can be drawn from these papers, although they must all be tentative given the small number of studies. First, the evidence for Oportunidades presented in Gertler and Fernald (2004) suggests that, on their own, the potential for conditional cash transfer programs to improve outcomes in early childhood may be limited. It may be necessary to combine cash transfers with other interventions to achieve large developmental impacts for young children. Second, the evidence from Argentina and Bolivia suggests that the returns to centerbased care, whether daycare or preschool, may be large. In both cases, children who participated in the intervention had significantly better cognitive and noncognitive outcomes. Third, the studies by Grantham-McGregor and her co-authors for Jamaica suggest that programs to increase early childhood stimulation and improve parenting can be an effective way of closing developmental gaps. By contrast, food transfers did little to improve the outcomes of the Jamaican children in the study sample. Many countries in Latin America spend large amounts of public resources on feeding programs. While there is evidence that nutrition programs can have positive long-term impacts, especially when they target pregnant mothers and continue through the first three years of a child's life (for example, Martorell 1999 on a well-known study in Guatemala), many government feeding programs do not meet these criteria. In Peru, for example, the "Glass of Milk" program is the largest social transfer; it reaches 44 percent of households with children ages 3 to 11 years, but appears to have no impact on nutritional outcomes (Stifel and Alderman 2003). Still, it is not clear how easily the results from Jamaica could be replicated on a larger scale. 


\section{Directions for policy and future research}

Economic theory suggests that there can be very high returns to investments in early childhood. The costs of making up deficits in cognitive and noncognitive development later on in life are often prohibitive, and the returns to many investments in skills formation in adulthood, such as job training programs, are often disappointingly low (Heckman et al. 1999). By contrast, research from the United States shows that carefully administered, intensive preschool programs can have very high returns. Evidence on the effectiveness of large-scale interventions like Head Start is more mixed, although generally positive. In Latin America and the Caribbean, the knowledge base on developmental shortfalls, on the relationship between deficits in early childhood and household socioeconomic status, child health, and parenting practices, and on the relative effectiveness of programs and policies is still disappointingly thin. Yet there is reason to believe that the economic costs of poor outcomes in early childhood in the region may be as large as or larger than those estimated for the United States. Careful analytical work is needed to establish the basic facts about ECD outcomes and deficits in the region, and to understand the causal pathways whereby a given characteristic of households, parents, or children determines outcomes in early childhood. A combination of economic theory, experimentation and careful evaluation is needed to identify specific policies and programs that are effective.

Recent research from a number of Latin American countries has applied tests of motor skills, cognitive development, and socio-emotional development that have been internationally normed. In theory, norming of the test instruments could have several advantages. Many of the tests have been shown to be correlated with various biological outcomes, as well as with “economic” measures such as school performance and wage outcomes in later life. For example, the TVIP vocabulary recognition test used by Gertler and Fernald (2004) and Paxson and Schady (2005) is the Spanish version of the PPVT, and performance on the PPVT at early ages has been shown to be a strong predictor of schooling and income in Great Britain and the United States. Also, because the tests are generally normed by comparing results with those of a "reference" population, the scores are, arguably, meaningful measures of a particular dimension of child welfare in some absolute sense. That is, the score on a given test can be used to provide answers to a question like "are children in the sample at the level they 'should' be for their age?” as well as questions like "do children of higher socioeconomic status in the sample perform better than those of lower socioeconomic status?” (For the latter question, there would be no need for reference populations for norming.) Finally, a number of the tests are age-normed, so that 
meaningful comparisons of developmental shortfalls can also be made across children of different ages.

The appeal of standardized, age-normed tests like many of those discussed above is similar to the appeal of using z-scores as measures of nutritional status, cut-offs for hemoglobin levels to establish anemia, or the fraction of households living below a dollar a day as an "international” measure of poverty. As such, these tests are likely to be an improvement on adhoc, country-specific tests. Like the measures of nutritional status and poverty, however, they depend crucially on the extent to which the norming has been done appropriately. This is a concern because the samples of children on whom the test was normed are often small, and may not provide a meaningful comparator to the population for which the test is used. For example, the TVIP was normed on 1,219 Mexican children and 1,488 Puerto Rican children (see http://www.agsnet.com/assessments/technical/tvip.asp for details). More research is needed to assess the extent to which the reference populations and age norms are appropriate. This is an area where testing and child development specialists could help make meaningful contributions.

With a better understanding of the various tests in hand, careful description of the basic facts about outcomes in early childhood in Latin America and the Caribbean is indispensable. What is the magnitude of the deficits (if any) in cognitive development, socio-emotional development, and motor development for population-based samples of young children in the region? How do these vary with household characteristics? A well established fact from the literature on health is that there is a "gradient" between socioeconomic status and health: Households of lower socioeconomic status, as measured by income, consumption, or education have higher levels of mortality and morbidity (for reviews for developing countries, see Behrman and Deolalikar 1988; Strauss and Thomas 1998). Similar findings are often reported in the literature on early childhood in the United States (Smith et al. 1997; Blau 1999; Guo and Harris 2000; Waldfogel et al. 2002; Auginbaugh and Gittleman 2003; Baum 2003; Ruhm 2004; Taylor et al. 2004; Brooks-Gunn and Markham 2005; Berger et al. 2005). Little about this is known for countries in Latin America and the Caribbean, although the results for Mexico, Brazil, and Ecuador suggest that socioeconomic gradients are likely to be important in the region. A clear understanding of what population groups are most vulnerable to shortfalls in child development in Latin America and the Caribbean is clearly indispensable for the appropriate targeting of programs.

Careful analysis is needed to establish whether there are periods at which faltering occurs in a particular dimension of early childhood development. For example, in most Latin American populations, the incidence of stunting, defined as height for age more than two standard 
deviations below that of a reference population, increases dramatically from about the age of 6 months to 24 months, and stabilizes (but does not recover) thereafter (Shrimpton et al. 2001). Are there comparable patterns in other dimensions of child wellbeing? Do specific health insults, inadequate resources, or low levels of stimulation have especially large negative effects on outcomes if they occur at a particular age in the life of a child? What deficits can be made up later in life? These are hard questions to answer with a single cross-section of data, both because it is not possible to disentangle age and cohort effects, and because a variety of child outcomes tend to be correlated over time. There are therefore important benefits to the collection of panel data that span the life of children from birth onwards. Indeed, because in-utero conditions are likely to have an effect on subsequent child development, panels would ideally begin during a mother's pregnancy.

Descriptive work is a critical building block for more ambitious attempts to combine economic theory and empirical analysis in an attempt to understand the causal pathways whereby characteristics of households or children affect a given dimension of development in early childhood. In the literature on the United States, there is considerable controversy about how low incomes lead to poor outcomes in early childhood. Low income is often associated with a lack of resources that can affect child development-for example, toys or reading material that stimulate cognitive development, or high quality day care. Children in low income households also tend to have worse health and nutritional status, and generally have parents with lower levels of education. In addition, lower incomes are associated with higher levels of maternal depression and home environments which are less nurturing, both of which are believed to have direct causal effects on outcomes. If there is a gradient between socioeconomic status and the formation of skills in early childhood in Latin America and the Caribbean, as seems likely, careful descriptive work informed by sound economic theory about how (and why) households make choices about childhood investments will be required to disentangle causal effects. Rich data sets with long histories and detailed information on household resources, maternal and child characteristics, parenting environments and access to social programs are particularly important in this regard.

In some cases, experimental evidence may also help recover "structural" parameters with a causal interpretation. The evaluation of PROGRESA is a good case in point. For the first years of the program, households were randomly assigned into a treatment group that received cash transfers and a control group. The program has been shown to have had positive effects on enrollment and attendance in school (Schultz 2004; Behrman et al. 2005). If the increase in child enrollment and attendance translates into higher school attainment as adults, it should be possible to (eventually) collect data on the outcomes of children born to the (randomly-selected) 
PROGRESA treatment and control groups to identify the causal effect of parental education on skills formation in early childhood. There are likely to be other cases in which exogenous sources of variation, either from naturally-occurring “experiments” or from deliberate program design, can be put to good use.

There are very high returns to careful implementation of a variety of interventions, and rigorous evaluation of their impact. It may be that seemingly unusual combinations of programs have the potential to have the largest impact. For example, the research by Gertler and Fernald (2004) suggests that, on their own, conditional cash transfer programs like Oportunidades may not lead to significant improvements in child cognitive development. This might argue for an intervention that focuses on parenting skills. The descriptive evidence in Paxson and Schady (2005) for Ecuador and the small-scale experimental evidence in the work by GranthamMcGregor and her co-authors in Jamaica both suggest that there could be very high returns to interventions that effectively improve parenting and the home environment. However, the high rate of attrition in many programs that seek to improve parenting in the United States, in particular home visiting programs, argues for innovative combinations of parenting programs with interventions that households are keen on participating in-perhaps, conditional cash transfer or feeding programs.

Careful consideration needs to be given to the evaluation of interventions. The literature on skill formation at early ages in the United States shows that there can be large differences between estimates of program effects based on experimental and non-experimental methods, and that it is hard to sign the direction of the bias ex-ante (Currie 2001; Gomby et al. 1999). In Latin America and the Caribbean, the strongest evidence on the impact of conditional cash transfer programs is based on carefully designed, experimental evaluations. A similar emphasis on innovative program design, careful implementation, and rigorous evaluation would build up the knowledge base on early childhood development in Latin America and the Caribbean. This would help identify programs and policies that ensure that children in the region can go on to have healthy and productive lives.

\section{References}

Aughinbaugh, A., and M. Gittleman. 2003. "Does Money Matter? A Comparison of the Effect of Income on Child Development in the United States and Great Britain.” Journal of Human Resources 38(2): 416-40.

Bassuk, E. L., L.F. Weinreb, R. Dawson, J.N. Perloff, J.C. Buckner. 1997. "Determinants of Behavior in Homeless and Low-Income Housed Preschool Children.” Pediatrics 100(1):92-100.

Baum, C. L. 2003. "Does Early Maternal Employment Harm Child Development? An Analysis of the Potential Benefits of Leave Taking.” Journal of Labor Economics 21(2): 409-48. 
Becker, G. 1964. Human Capital: A Theoretical and Empirical Analysis with Special Reference to Education. New York: Columbia University Press.

Becker, G., and N. Tomes. 1979. “An Equilibrium Theory of the Distribution of Income and Intergenerational Mobility.” Journal of Political Economy 87(6): 1153-1189.

Becker, G., and N. Tomes. 1986. "Human Capital and the Rise and Fall of Families." Journal of Labor Economics 4(3): S1-S39.

Behrman, J., and A. Deolalikar. 1988. "Health and Nutrition”, in Handbook of Development Economics, Vol. 1, Eds.: H. Chenery and T.N. Srinivasan. Amsterdam: North Holland Press, pp. 631-711.

Behrman, J., Y. Cheng, and P. Todd. 2004. "Evaluating Pre-school Programs when Length of Exposure to the Program Varies: A Nonparametric Approach.” Review of Economics and Statistics 86(1): 108-32.

Behrman, J.R., S.W. Parker and P. E. Todd. 2004. "Medium-Term Effects of the Oportunidades Program Package, Including Nutrition, on Education of Rural Children Age 0-8 in 1997.” Unpublished manuscript.

Behrman, J., P. Sengupta, and P. Todd. 2005. "Progressing through Progresa: An Impact Assessment of a School Subsidy Experiment in Mexico.” Economic Development and Cultural Change 54(1): 237-76.

Ben Porath, Y. 1967. "The Production of Human Capital and the Life Cycle of Earnings.” Journal of Political Economy 75(4): 352-65.

Berger, L., C. Paxson, and J. Waldfogel. 2005. “Income and Child Development.” Unpublished manuscript.

Berlinski, S. and S. Galiani. 2005. "The Effect of a Large Expansion of Pre-Primary School Facilities on Preschool Attendance and Maternal Employment.” Unpublished manuscript.

Berlinski, S., S. Galiani, and P. Gertler. 2005. "Public Pre-primary Schooling and Primary School Performance.” Unpublished manuscript.

Blau, D and J. Currie. 2004. "Preschool, Day Care, and Afterschool Care: Who's Minding the Kids?” National Bureau of Economic Research Working Paper 10670. Cambridge, MA.

Blau, D.M. 1999. “The Effect of Income on Child Development.” Review of Economics and Statistics 81(2): 261-276.

Bradley, R.H. 1993. "Children’s Home Environments, Health, Behavior, and Intervention Efforts: A Review Using the HOME Inventory as a Marker Measure.” Genetic, Social, and General Psychology Monographs, 119, 437-490.

Bradley, R.H., R.F. Corwyn, H.P. McAdoo, and C.G. Coll. 2001. "The Home Environments of Children in the United States Part I: Variations by Age, Ethnicity, and Poverty Status." Child Development 72(6): 1844-1867.

Brooks-Gunn, J. and L.B. Markman. 2005. "The Contribution of Parenting to Ethnic and Racial Gaps in School Readiness.” The Future of Children 15(1): 139-68.

Brooks-Gunn, J., L.Berling and A. Fuligni. 2000. "Early Childhood Intervention Programs: What About the Family?” Handbook of Early Childhood Intervention, $2^{\text {nd }}$ ed. J.P. Schonkoff and S. J. Meisels, eds. New York: Cambridge University Press.

Caldwell, B.M. and R.H. Bradley, 1984. Administration Manual (Revised Edition): Home Observation for Measurement of the Home Environment. Little Rock, AR: University of Arkansas.

Carneiro, P. and J. Heckman. 2002. "The Evidence on Credit Constraints in Post-Secondary Schooling.” The Economic Journal 112(482): 705-34.

Carneiro, P. and J. Heckman. 2003. "Human Capital Policy." National Bureau of Economic Research Working Paper 9495. Cambridge, MA.

Connolly, S., J.Micklewright, and S. Nickell. 1992. "The Occupational Success of Young Men who left School at Sixteen.” Oxford Economic Papers 44: 460-479. 
Cunha, F., J. Heckman, L. Lochner, D. Masterov. 2005. "interpreting the Evidence on Life Cycle Skill Formation.” 2005. NBER Working Paper 11331, Cambridge, MA.

Currie,J. 2001. "Early Childhood Education Programs.” The Journal of Economic Perspectives, 15(2): 213-238.

Currie, J. and D. Thomas. 2000. "School Quality and the Longer-Term Effects of Head Start." The Journal of Human Resources 35(4): 755-774.

Currie, J. and D. Thomas. 1995. “Does Head Start Make a Difference?” American Economic Review 85(3): 341-64.

Currie, J. and D. Thomas. 1999. "Early Test Scores, Socioeconomic Status and Future Outcomes.” National Bureau of Economic Research Working Paper 6943. Cambridge, MA.

Danziger, S. and J. Waldfogel. 2000. "Investing in Children: What do we Know? What Should We Do?” CASE paper 34. Centre for Analysis of Social Exclusion, London, UK.

Donohue, J. and P. Siegelman. 1998. "Allocating Resources Among Prisons and Social Programs in the Battle Against Crime.” Journal of Legal Studies 27(1): 1-43.

Feinstein, L. 2003. "Inequality in the Early Cognitive Development of British Children in the 1970 Cohort.” Economica 70: 73-97.

Fernald, L.C., L.M. Neufeld, L.R. Barton, et al. 2005 "Parallel Deficits in Linear Growth and Mental Development in Low-Income Mexican Infants in the Second Year of Life.” Public Health Nutrition, in press.

Fryer, R.G. and S.D. Levitt. 2004. "Understanding the Black-White Test Score Gap in the First Two Years of School.” The Review of Economics and Statistics 86(2): 447-464.

Garces, E., D. Thomas, J. Currie. 2002. “Longer-Term Effects of Head Start.” The American Economic Review 92(4): 999-1012.

Gertler, P.J. and L.C. Fernald. 2004. "The Medium Term Impact of Oportunidades on Child Development in Rural Areas.” Unpublished manuscript.

Gomby, D., P. Culross and R. Behrman. 1999. "Home Visiting: Recent Program EvaluationsAnalyses and Recommendations.” The Future of Children 9(1): 4-26.

Grantham-McGregor, S.M., C.A. Powell, S.P. Walker and J.H. Himes. 1991. “Nutritional Supplementation, Psychosocial Stimulation, and Mental Development of Stunted Children: The Jamaican Study.” Lancet 338:1-5.

Grantham-McGregor, S.M., S.P. Walker, S.M. Chang and C.A. Powell. 1997. "Effects of Early Childhood Supplementation with and Without Stimulation on Later Development in Stunted Jamaican Children.” American Journal of Clinical Nutrition 66: 247-253.

Griliches, Z. 1977. "Estimating the Returns to Schooling: Some Econometric Problems.” Econometrica 45(1): 1-22.

Guo, G., and K.M. Harris. 2000. "The Mechanisms Mediating the Effects of Poverty on Children’s Intellectual Development.” Demography 37(4): 431-447.

Gupta, V.B., N.M. Nwosa, T.A. Nadel, S. Inamdar. 2001. "Externalizing Behaviors and Television Viewing in Children of Low-Income Minority Parents.” Clinical Pediatrics 40(6): 337-41. 
Halpern, R., F. Barros, B. Horta, and C. Victora. 1996. "Desenvolvimento neuropsicomotor aos 12 meses de idade em uma coorte de base populacional no Sul do Brasil: diferenciais conforme peso ao nascer e renda familiar.” Cad. Saúde Púb. 12(Supl. 1): 73-78.

Heckman, J., R. Lalonde, and J Smith. 1999. "The Economics and Econometrics of Active Labor Market Programs.” In O. Ashenfelter and D. Card., eds., Handbook of Labor Economics, vol. 3A, Amsterdam: Elsevier.

Heckman, J. and Y. Rubinstein. 2001. "The Importance of Nonccognitive Skills: Lessons from the GED Testing Program.” American Economic Review 91(2): 145-49.

Jutte, D.P., A. Burgos, F. Mendoza, C.B. Ford, L.C. Huffman. 2003. "Use of the Pediatric Symptom Checklist in a Low-Income, Mexican American Population.” Archives of Pediatrics \& Adolescent Medicine 157(12):1169-76.

Lee, V.E., J. Brooks-Gunn, E. Schnur, F.R. Liaw. 1990. “Are Head Start Effects Sustained? A Longitudinal Follow-Up Comparison of Disadvantaged Children Attending Head Start, No Preschool, and Other Preschool Programs.” Child Development 61(2):495-507.

Love, J., et al. 2002. "Making a Difference in the Lives of Infants and Toddlers and Their Families: The Impacts of Early head Start.” U.S. Department of Health and Human Services.

Lozoff, B., E. Jimenez, A.W. Wolf. 1991. "Long-Term Developmental Outcome of Infants with Iron Deficiency.” New England Journal of Medicine 5(325)(10): 687-94.

Magnuson, K.A., C.J. Ruhm, J. Waldfogel. 2004. “Does Prekindergarten Improve School Preparation and Performance?” National Bureau of Economic Research Working Paper 10452. Cambridge, MA.

Marchman, V. A., C. Martine-Sussmann. 2002. “Concurrent Validity of Caregiver/Parent Report Measures of Language for Children Who are Learning Both English and Spanish.” Journal of Speech, Language, and Hearing Research 45(5):983-97.

Martorell, R. 1999. “The Nature of Child Malnutrition and its Long-Term Implications.” Food and Nutrition Bulletin 20(3): 288-292.

Munoz, F., C. Quilodran, P. Velasquez, C. Niedmann, A Baeza, G. Silva and M Osorio. 1989. "Acquirement of the Spanish vocabulary among rural and urban students of the 9th region.” Revista Chilena de Pediatria 60(6): 354-358.

O'Connor, D.L., R. Hall, D. Adamkin, N. Auestad, M. Castillo, W.E. Connor.2001. “Growth and Development in Preterm Infants Fed Long-Chain Polyunsaturated Fatty Acids: A Prospective, Randomized Controlled Trial.” Pediatrics 108(2):359-71.

Paxson, C., N. Schady. 2005. "Cognitive Development among Young Children in Ecuador: The Roles of Wealth, Health and Parenting.” Policy Research Working Paper No. 3605. World Bank, Washington, D.C.

Powell, C., H. Baker-Henningham, S. Walker, J. Gernay, and S. Grantham-McGregor. 2004. "Feasibility of Integrating Early Stimulation into Primary Care for Undernourished Jamaican Children: Cluster Randomised Controlled Trial.” British Medical Journal 329(7457)89: 1-4.

Reynolds, A.J., J.A. Temple. 1998. "Extended Early Childhood Intervention and School Achievement: Age Thirteen Findings from the Chicago Longitudinal Study." Child Development 69(1):231-46. 
Robertson, D., and J. Symons. 2003. "Do Peer Groups Matter? Peer Group versus Schooling Effects on Academic Attainment.” Economica 70:31-53.

Rodríguez, V.L., J.O. Prewitt Diaz. 1990. "Correlations among GPA and Scores on the Spanish Version of WISC-R and the Woodcock-Johnson Achievement Subtests for 10- to 12Year-Old Puerto Rican Children.” Psychological Reports 66(2):563-6.

Rosselli, M, A. Ardila, J.R. Bateman, M. Guzman. 2001. "Neuropsychological Test Scores, Academic Performance, and Developmental Disorders in Spanish-Speaking Children.” Developmental Neuropsychology 20(1):355-73.

Ruhm, C.J. 2004. “Parental Employment and Child Cognitive Development.” Journal of Human Resources 39(1):155-192.

Schultz , T.P. 2004. "School Subsidies for the Poor: Evaluating the Mexican Progresa Poverty Program.” Journal of Development Economics 74(1): 199-250.

Schweinhart, L. J.2005. “The High/Scope Perry Preschool Study Through Age 40: Summary, Conclusions, and Frequently Asked Questions.” High/Scope Press.

Shrimpton, R., C. Victora, M. De Onis, R. Costa Lima, et al. 2001. "Worldwide Timing of Growth Faltering: Implications for Nutritional Interventions.” Pediatrics 107:75-81.

Smith, J.R., J. Brooks-Gunn and P.K. Klebanov, 1997. "Consequences of Living in Poverty for Young Children's Cognitive and Verbal Ability and Early School Achievement.” In : Duncan, J. Brooks-Gunn J. (eds.) Consequences of Growing up Poor, Russell Sage Foundation, New York, 132-189.

Stifel, D., and H. Alderman. 2003. "The "Glass of Milk" Subsidy Program and Malnutrition in Peru.” Policy Research Working Paper No. 3089. World Bank, Washington, D.C.

Strauss, J., and D. Thomas. 1998. “Health, Nutrition, and Economic Development.” Journal of Economic Literature 36: 436-82.

Taylor, B., E. Dearing and K. McCartney. 2004. "Incomes and Outcomes in Early Childhood.” Journal of Human Resources 39(4):980-1007.

Todd, P.E., and K.I. Wolpin. 2003. "On the Specification and Estimation of the Production Function for Cognitive Achievement.” The Economic Journal 113: F3-F33.

Umbel, V.M., B.Z. Pearson, M.C. Fernandez, and D.K. Oller. 1992. "Measuring bilingual children's receptive vocabularies.” Child Development 63(4): 1012-20.

Victora, C., F. Barros, and J. Vaughan. 1989. Epidemiologia da Desigualdade, Sao Paulo: Hucitec.

Waldfogel, J., W. Han, and J. Brooks-Gunn. 2002. "The Effects of Early Maternal Employment on Child Cognitive Development.” Demography 30(2): 369-92.

Walker SP, S.M. Grantham-Mcgregor, C.A. Powell, S.M. Chang. 2000. "Effects of Growth Restriction in Early Childhood on Growth, IQ, and Cognition at Age 11 to 12 Years and the Benefits of Nutritional Supplementation and Psychosocial Stimulation.” The Journal of Pediatrics 137(1): 36-41.

World Bank. 2005a. World Development Report 2006: Equity and Development. The World Bank and Oxford University Press, New York.

World Bank. 2005b. Development Database Platform. Washington, D.C.. Available online at available at http://www.worldbank.org/data/onlinedatabases/onlinedatabases.html; accessed October 1, 2005. 
Table 1: Gross Preprimary Enrollment Rates, 2000

\begin{tabular}{|c|c|c|c|}
\hline Country & $\begin{array}{c}\text { Gross preprimary } \\
\text { enrollment }\end{array}$ & $\begin{array}{c}\text { Gross preprimary } \\
\text { enrollment: GDP- } \\
\text { adjusted } \\
\text { (weighted) }\end{array}$ & $\begin{array}{c}\text { Gross preprimary } \\
\text { enrollment: GDP- } \\
\text { adjusted } \\
\text { (unweighted) }\end{array}$ \\
\hline Argentina & 60.4 & $-22.6^{* * *}$ & $-19.6^{* * *}$ \\
\hline Barbados & 80.3 & -7.7 & -2.6 \\
\hline Bolivia & 46.3 & $11.5^{* * *}$ & $14.9 * * *$ \\
\hline Brazil & 61.5 & 7.1 & 4.5 \\
\hline Chile & 77.5 & $12.3^{*}$ & $10.9 * *$ \\
\hline Colombia & 37.0 & -6.5 & $-5.8 * *$ \\
\hline Costa Rica & 90.8 & $30.7 * * *$ & $29.5^{* * *}$ \\
\hline Cuba & 108.7 & & \\
\hline Dominican Republic & 35.1 & $-11.4 * *$ & $-11.5 * * *$ \\
\hline Ecuador & 69.6 & $32.4 * * *$ & $35.0 * * *$ \\
\hline El Salvador & 43.9 & -0.6 & -0.2 \\
\hline Guatemala & 51.1 & $10.2^{* * *}$ & $11.6^{* * *}$ \\
\hline Honduras & 21.3 & $-12.1 * * *$ & $-9.3 * * *$ \\
\hline Jamaica & 82.0 & $29.2 * *$ & $29.9 * * *$ \\
\hline Mexico & 75.3 & 4.9 & 3.4 \\
\hline Nicaragua & 26.8 & $-5.9 * *$ & -1.9 \\
\hline Panama & 45.2 & $-14.3^{* *}$ & $-16.2 * * *$ \\
\hline Paraguay & 28.9 & -10.0 & $-8.2 * * *$ \\
\hline Peru & 59.5 & $15.9 * * *$ & $16.3^{* * *}$ \\
\hline Venezuela & 51.6 & $-14.5^{* *}$ & $-15.8 * * *$ \\
\hline $\begin{array}{l}\text { Latin America and } \\
\text { Caribbean }\end{array}$ & 61.1 & 4.3 & 10.9 \\
\hline
\end{tabular}

Note: Regressions with Huber-White corrected standard errors. * Significant at the 10 percent level, ** at the 5 percent level, *** at the 1 percent level. Sample size is 144 countries.

Source: World Bank databases. 


\section{Figure 1: Cognitive development of children age 36-72 months in Ecuador}
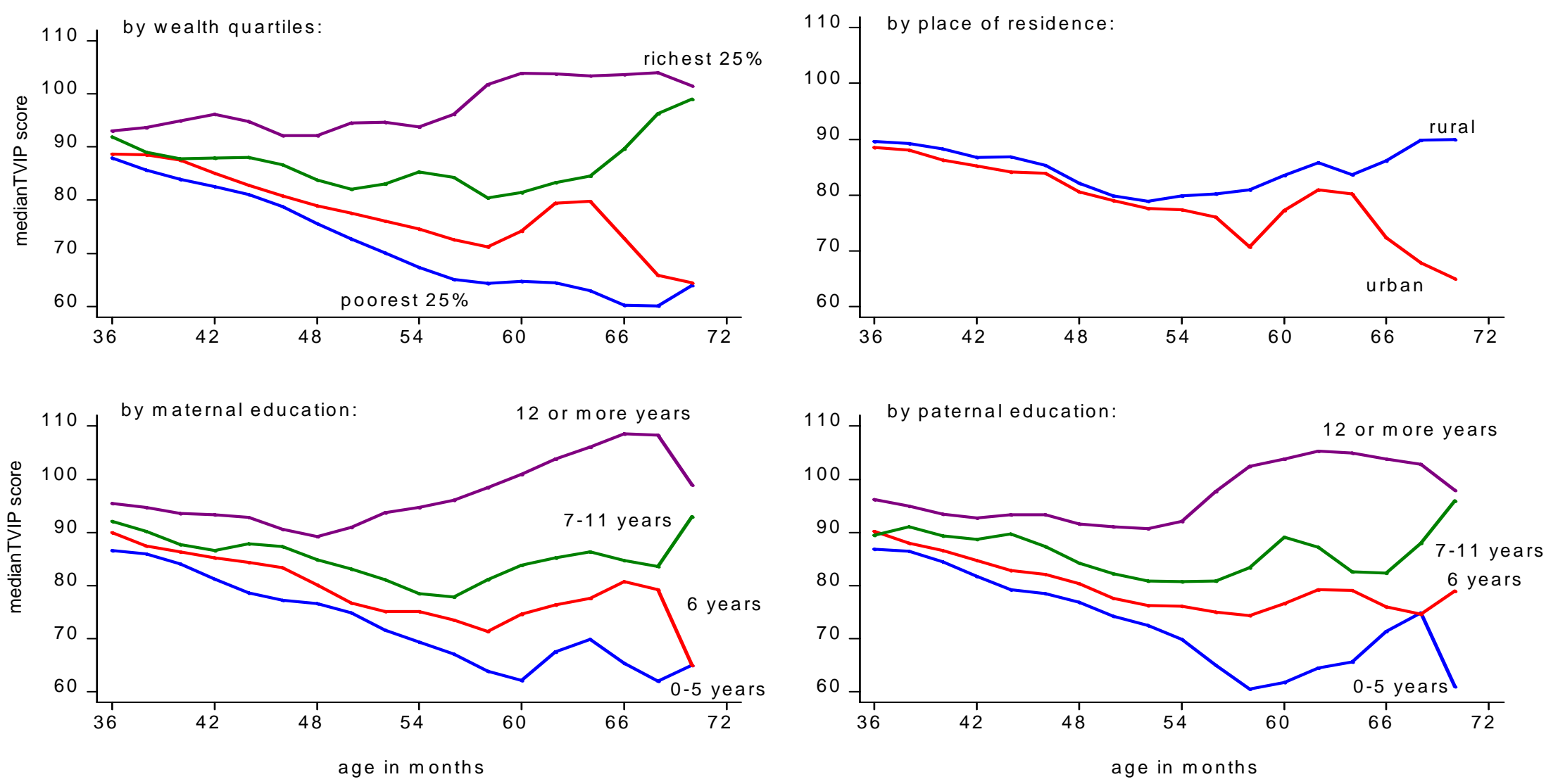

Source: Paxson and Schady (2005). 
C:IDOCUME 1।HSLADO 1\LOCALS 1\Temp\notesD9A159|Schady-ECD-011106.doc 01/19/2006 5:54:00 PM 